\title{
Determinants of Diffusion of Animal Husbandry Innovations among Dairy Farmers of Andhra Pradesh, India
}

\author{
G. Triveni $^{\text {1* }}$, G. R. K. Sharma ${ }^{2}$, Ch. Satyanarayana ${ }^{3}$, K. Sarjan Rao ${ }^{4}$ \\ and T. Raghunandhan ${ }^{5}$ \\ ${ }^{I}$ Department of Veterinary Extension, College of Veterinary Science, Tirupati, India \\ ${ }^{2}$ College of Veterinary Science, Tirupati, India \\ ${ }^{3}$ College of Veterinary Science, Hyderabad, India \\ ${ }^{4}$ DSA, Sri Venkateswara Veterinary University, Tirupati, India \\ ${ }^{5}$ College of Veterinary Science, Korutla, Telangana, India \\ *Corresponding author
}

\begin{tabular}{l} 
K e y w o r d s \\
Diffusion, \\
Prediction, \\
Correlation, \\
Multiple regression \\
\hline Article Info \\
\hline $\begin{array}{l}\text { Accepted: } \\
\text { 15 March } 2020 \\
\text { Available Online: } \\
\text { 10 April } 2020\end{array}$ \\
\hline
\end{tabular}

\section{A B S T R A C T}

To sustain dairy farming as a rural livelihood and to meet the growing demand of milk, necessitates dissemination of technologies/innovations for improving the farm's output. There is also a need to understand how far existing innovations are diffused to the farmers and factors influencing diffusion and/or rejection. Based on the highest cattle population and best rank in adoption of recommended dairy innovations three districts namely Visakhapatnam, Krishna and Chittoor were selected from each region of Andhra Pradesh respectively. From the 18 villages of the selected 3 districts, 20 dairy farmers were selected from each village and finally 360 respondents were selected for the study. The computed r-values between profile characters and diffusion, viz., land holding, experience, income, decision making ability, economic orientation, scientific orientation, attitude and communication channels were positively and significantly correlated with diffusion of innovations. The step down multiple regression analysis done at last step for prediction of influence of independent variables on diffusion revealed that, experience, income, economic orientation, attitude and communication channels were significant $(\mathrm{P} \leq 0.01)$ in positive direction while age is significant $(\mathrm{P} \leq 0.01)$ in negative direction. All these variables focused on technology dissemination for diffusion of dairy innovations into farming communities in the study area.

\section{Introduction}

Dairying is recognized as an important source of income for small and marginal farmers of India because, on an average 22-26 per cent of the income of rural households is contributed by milk. Majority of milk producers have one or two milch animals and account for about 70 per cent of milk production. Lack of other lucrative and alternate employment opportunities often make dairying the only viable option for 
many small and marginal farmers. To sustain dairy farming as rural livelihood and to meet the growing demand of milk, necessitates dissemination of technologies/innovations for improving the farm's output (Margarita et al., 2013). On the other hand, farmers have always looked for new technologies which yield higher income, greater knowledge and reach through available channels of communication. In this scenario, the major issue of concern is how to diffuse or scale up these technologies to reach more low-resource farmers. There is also a need to understand how far existing innovations are diffused to the farmers and factors influencing diffusion and/or rejection (Surkar et al., 2014).

Studies on diffusion of innovations/ determinants for effective diffusion of dairy technologies are very few and were not well documented. Keeping this in view, the present study was undertaken to study the diffusion of innovations and determinants of diffusion among dairy farmers of Andhra Pradesh.

\section{Materials and Methods}

The present study was carried out purposively in three regions i.e., North Coastal, Coastal and Rayalaseema regions of Andhra Pradesh as the investigator and the technologies generated by the University belong to the same area. Based on the highest cattle population and best rank in adoption of recommended dairy innovations three districts namely Visakhapatnam, Krishna and Chittoor were selected from each region respectively.

Three mandals from each district and two villages from each mandal, i.e., 6 villages from each district totaling to 18 villages were selected through simple random sampling technique. From each village 20 dairy farmers were selected through simple random sampling and finally 360 respondents were selected for the study.
Diffusion for the present study is operationalized as, the time taken by the dairy farmer to implement the innovation recommended, to the time from which the farmer is aware of the innovation. The continuous adoption of an innovation for a period more than three years by the farmer is considered as diffusion for that particular innovation into the social system.

To know the effect of socio-personal variables on diffusion of innovations a correlation analysis was carried out. Since correlation does not capture the interaction effect, for prediction of the selected independent variables that contribute to the variation in the diffusion process, a multiple linear regression analysis was carried out. Further, step down multiple regression was done to identify the independent variables that accounted for variation in diffusion levels of the respondents.

\section{Results and Discussion}

Correlation coefficient was computed to find out the relationship between socio-profile characteristics of dairy farmers and diffusion of dairy innovations. The computed r-values between profile characters viz., land holding, experience, income, decision making ability, economic orientation, scientific orientation, attitude and communication channels were positively and significantly correlated with rate of diffusion at $1 \%$ level of probability while the variable information seeking behaviour was correlated significantly and positively at $5 \%$ level of probability.

The variable age had shown significant and negative correlation with diffusion of respondents at 5\% level of probability. Gender, education, herd size, milk production, decision making ability and risk bearing ability were non-significantly correlated with diffusion among dairy farmers (Table 1-3). 
Prediction of the contribution of independent variables on diffusion among dairy farmers

In the single variable relationship, correlation coefficients empirically measure the relationship between dependent variables and selected profile characteristics of the farmers. This procedure does not capture the interaction effect. For prediction of the selected independent variables that contribute to the variation in the diffusion process a multiple linear regression analysis was carried out. Perusal of the results indicated that the variables land holding, experience, income, economic orientation and communication channels had positive and significant regression coefficients at 1 per cent level of probability while the variable attitude had shown positive and significant regression coefficient and the variable age had exerted negative and significant regression coefficient at 5 per cent level of probability.

The value $\mathrm{R}^{2}$ (0.574) indicated that all the independent variables put together explained a variation in the diffusion of dairy innovations by the dairy farmers to an extent of 57.4 per cent. The computed F-value $\left(13.375^{* *}\right)$ was found to be highly significant. Based on the $\mathrm{R}^{2}$ and the test null hypothesis was rejected and concluded that the score on 17 independent variables explained a significant amount of variation on the rate of diffusion of dairy innovations by the respondents.

Table 3 shows that step down regression analysis was done to identify the independent variables that accounted for variation in diffusion levels of the respondents. The results of Table 3 confirmed that, eight variables significantly contributed to 55.8 Per cent variation in the rate of diffusion process. The variance ratio is (9.845) which is highly significant at $1 \%$ level of probability. The variables experience, income, economic orientation, attitude and communication channels have exerted positive and significant regression coefficients at $1 \%$ level while the variables land holding, and milk production have shown positive and significant regression coefficients at 5\% level of probability. The variable age had shown negative and significant regressions coefficient at $5 \%$ level of probability.

\section{Relational analysis of diffusion with profile characteristics of dairy farmers}

The results of the present study revealed that majority of the dairy farmers belonging to middle age group adopted recommended technologies and shared the technologies with members outside their societal boundaries which helped the innovation to diffuse among different farming communities. This trend showed a descending order as the age of the respondents advanced from young to old age groups. Both male and female members were involved in diffusion process almost to an equal extent. The awareness among women members increased after the cluster approach i.e., formation of women self help groups. The role of women is also equivalently contributing to the diffusion process of dairy innovations which resulted in nonsignificance of gender in diffusion process. The results revealed that irrespective of the level of education, farmers diffused the practices that were profitable, easily demonstrable and compatible with in their situations based on their rich experience, practical knowledge and information seeking behavior (Lahoti et al., 2012).

Land holding was positively correlated with diffusion at $1 \%$ level of probability. Land is a resource factor for any farmer which makes him decide whether/not to adopt an innovation. Without a minimal land holding the farmers feel handicapped to adopt/diffuse 
any innovation, which is the case with small and marginal farmers. Medium to large farmers with sizeable land holdings were only involved in the diffusion process which resulted in above significance. Farmers with ample experience in dairy farming adopted recommended dairy innovations to a considerable extent and acted as an interconnecting link for diffusion of these innovations into social system and thus the above significance. Herd size was positively but non-significantly correlated with diffusion. As the size of herd increased, the farmer concentrated more on adoption of innovations in his own enterprise, which therefore resulted in non-significant relationship. Though herd size is more, number of animals in lactation are only two on an average and milk yield/ animal / day is also less (4.5 lit / animal / day on an average) which showed non-significant relation with rate diffusion. Income is the guiding force to motivate any farmer to exercise / implement any new practice in his farm. Farmers with medium to high level of income are enthusiastic to diffuse the innovations outside their social boundaries and vice-versa with low income groups and hence significant relation.

The variable innovativeness exerted a positive but non-significant correlation with rate of diffusion of dairy innovations. Majority of the farmers in the study area had low levels of education, small land holdings, medium income, medium scientific orientation and medium to low risk bearing ability which may be the plausible reasons hindering them from being innovative in diffusing the new technologies. The findings gain support from Loganandhan and Singh (2003). Decision making ability requires sound knowledge and skills as it is a deciding factor to diffuse any adopted innovation. The respondents' scientific orientation, economic orientation and information seeking behaviour contributed for effective decision making, which culminated in efficient diffusion process. Risk bearing ability is an essential character to diffuse any new practice into farming communities. The present trend in the study area was due to less variation in the sample. Economic orientation is a desire on the part of a dairy farmer for achieving more profit by means of adopting and diffusing more number of scientific practices into his farm. Hence, the relationship was found to be significant. The findings had support of Prajapati (2015). The possible reason might be that an individual with medium scientific orientation will try to accept improved diary technologies and diffuse those technologies which satisfy their needs in their farms with more accuracy than others and hence a significant relationship.

Majority of the farmers had medium to low level of perception about dairy innovations recommended which may be due to unawareness of the benefits that can be derived and therefore a non-significant relationship. A dairy farmer with positive attitude tend to look at the choice of technologies given to him and choose the most appropriate and feasible innovation which improves his farm income. The farmers showed positive attitude which is a good trend for diffusion of innovations. The findings of the study are corroborated by Meena et al., (2012).

The positive and significant relationship with information seeking behaviour might be due to the positive mind set to seek latest scientific information to keep abreast of latest advancements which help to run the dairy enterprise in profitable lines. The communication channels like newspapers, agricultural magazines, radio, television, mobile phones, multimedia modules, mobile apps etc., are providing plethora of information on new scientific advances 
through various modes of dissemination and hence a significant positive relation with diffusion of dairy innovations.

Prediction of the contribution of independent variables on rate of diffusion of dairy farmers

The results of Table 3 revealed that, multiple regression analysis of variables experience, attitude and communication channels showed positive and significant coefficients at $1 \%$ level of probability while land holding, herd size and income were found to have positive and significant coefficients at 5\% level of probability. The value of $\mathrm{R}^{2}(0.574)$ indicated that all the variables put together explained variation in rate of diffusion to an extent of
57.4 per cent. The computed F-value (13.375) was significant at $1 \%$ level. The step down multiple regression analysis done at last step for prediction of influence of independent variables on rate of diffusion revealed that, experience, income, economic orientation, attitude and communication channels were significant $(\mathrm{P} \leq 0.01)$ in positive direction while age is significant $(\mathrm{P} \leq 0.01)$ in negative direction. The variables land holding and milk production were significant in positive direction at 5\% level of probability. All these variables explained 55.8 per cent variation and F-value is significant (9.845) at $1 \%$ level. All these variables focused on technology dissemination for diffusion of dairy innovations into farming communities in the study area.

Table.1 Relationship between diffusion of dairy innovations and profile characteristics of dairy farmers

\begin{tabular}{|c|c|c|}
\hline S.No. & Independent variables & Correlation coefficient r-value \\
\hline 1. & Age & $-0.208 * *$ \\
\hline 2. & Gender & $0.119 \mathrm{NS}$ \\
\hline 3. & Education & $0.128 \mathrm{NS}$ \\
\hline 4. & Land holding & $0.489 *$ \\
\hline 5. & Experience & $0.308^{* *}$ \\
\hline 6. & Herd size & $0.210 \mathrm{NS}$ \\
\hline 7. & Milk production & $0.212 \mathrm{NS}$ \\
\hline 8. & Income & $0.492 * *$ \\
\hline 9. & Innovativeness & $0.143 \mathrm{NS}$ \\
\hline 10. & Decision making ability & $0.477 * *$ \\
\hline 11. & Risk bearing ability & $0.138 \mathrm{NS}$ \\
\hline 12. & Economic orientation & $0.350 * *$ \\
\hline 13. & Scientific orientation & $0.385^{* *}$ \\
\hline 14. & Perception & $0.154 \mathrm{NS}$ \\
\hline 15. & Attitude & $0.404 * *$ \\
\hline 16. & $\begin{array}{l}\text { Information seeking } \\
\text { behaviour }\end{array}$ & $0.347^{*}$ \\
\hline 17. & Communication channels & $0.428 * *$ \\
\hline
\end{tabular}


Table.2 Multiple linear regression analysis of independent variables with diffusion of dairy innovations

\begin{tabular}{|r|l|c|c|c|}
\hline S.No. & \multicolumn{1}{|c|}{ Variables } & Regression coefficient (b) & SER & t-value \\
\hline $\mathbf{1 .}$ & Age & 2.831 & & \\
\hline $\mathbf{2 .}$ & Gender & 1.318 & 1.414 & $1.903^{\mathrm{NS}}$ \\
\hline $\mathbf{3 .}$ & Education & 3.817 & 0.429 & 1.816 \\
\hline $\mathbf{4 .}$ & Land holding & 4.321 & 1.616 & $2.685^{*}$ \\
\hline $\mathbf{5 .}$ & Experience & 2.138 & 2.314 & $4.012^{* *}$ \\
\hline $\mathbf{6 .}$ & Herd size & 1.474 & 0.782 & $2.506^{*}$ \\
\hline $\mathbf{7 .}$ & Milk production & 2.985 & 0.523 & 1.924 \\
\hline $\mathbf{8 .}$ & Income & 2.318 & 1.995 & $1.987^{*}$ \\
\hline $\mathbf{9 .}$ & Innovativeness & 3.120 & 0.626 & $1.913^{\mathrm{NS}}$ \\
\hline $\mathbf{1 0 .}$ & Decision making ability & 2.945 & 1.845 & 1.691 \\
\hline $\mathbf{1 1 .}$ & Risk bearing ability & 2.868 & 0.782 & 1.826 \\
\hline $\mathbf{1 2 .}$ & Economic orientation & 1.279 & 1.087 & $2.129^{\mathrm{NS}}$ \\
\hline $\mathbf{1 3 .}$ & Scientific orientation & 1.065 & 0.531 & 2.014 \\
\hline $\mathbf{1 4 .}$ & Perception & 2.383 & 0.310 & 1.894 \\
\hline $\mathbf{1 5 .}$ & Attitude & 1.488 & 0.583 & $4.089^{* *}$ \\
\hline $\mathbf{1 6 .}$ & Information seeking & 0.614 & 1.934 \\
\hline & behavior & 4.734 & & \\
\hline $\mathbf{1 7 .}$ & Communication channels & 1.521 & $3.113^{* *}$ \\
\hline
\end{tabular}

$\mathrm{R}^{2}=0.574, \quad \mathrm{~F}$ value $=13.375 * * \quad *$ Significant at $\mathrm{P}<0.05 \quad * *$ Significant at $\mathrm{P}<0.01$

Table.3 Step down multiple regression analysis for predicting the influence of profile characteristics with diffusion among dairy farmers

\begin{tabular}{|c|l|c|c|c|}
\hline S. No. & \multicolumn{1}{|c|}{ Variables } & $\begin{array}{c}\text { Regression } \\
\text { coefficient }(\mathbf{b})\end{array}$ & SE & t value \\
\hline $\mathbf{1 .}$ & Age & -2.843 & 0.764 & $-2.345^{* *}$ \\
\hline $\mathbf{2 .}$ & Land Holding & 3.728 & 1.412 & $2.484^{*}$ \\
\hline $\mathbf{3 .}$ & Experience & 4.236 & 2.115 & $3.892^{* *}$ \\
\hline $\mathbf{4 .}$ & Milk production & 2.858 & 0.975 & $3.508^{*}$ \\
\hline $\mathbf{5 .}$ & Income & 3.263 & 1.981 & $3.898^{* *}$ \\
\hline $\mathbf{6 .}$ & Economic orientation & 2.383 & 0.583 & $4.089^{* *}$ \\
\hline $\mathbf{7 .}$ & Attitude & 2.486 & 0.982 & $3.104^{* *}$ \\
\hline $\mathbf{8 .}$ & Communication channels & 4.114 & 2.624 & $3.005^{* *}$ \\
\hline
\end{tabular}

The results of the study indicated that the variables land holding, experience, income, economic orientation and communication channels had positive and significant regression coefficients at 1 per cent level of probability while the variable attitude had shown positive and significant regression coefficient at 5 per cent level of probability. It is of hope that, dissemination of latest scientific information on production aspects in local language through radio and television in kisan programs daily in the evening 
followed by meetings, trainings, campaigns and supportive literature would help in improving rate of diffusion of dairy innovations among farming communities.

\section{References}

Lahoti S.R, Chole S.R. and Rathi N.S 2012. Role of women in dairy farming. Indian Journal of Dairy Science, 65(5).

Loganandhan N. Singh 2003. Adoption of organic farming, profile and motives of farmers. Indian Journal of Extension Education, 39(1\&2): 35-40.

Margarita Genius, Phoebe Koundouri, Clline Nauges 2013. Information transmission in irrigation technology adoption and diffusion - social learning, extension services and spatial effects. Journal of Agricultural Economics, 96(1): 328-
344.

Meena M.S, Singh K.M, Malik B.S, Meena B.S and Kanwat M 2012. Knowledge index for measuring knowledge and adopting scientific methods in treatment of reproductive problems in dairy animals Journal of Agricultural Science, 4(10): 81-88.

Prajapati J.V 2015. Extent of Adoption of Low-cost Technologies of Animal Husbandry by Tribal Dairy Farm women. Indian Research Journal of Extension Education, 15(4): Special Issue: $47-50$.

Surkar S.H, Sawarkar S.W, Kolhe R.P and Basunathe V.K 2014. Adoption of Quality Milk Production practices by dairy farmers in Wardha district of Maharashtra. Agricultural Rural Development, 1:1-4.

\section{How to cite this article:}

Triveni, G., G. R. K. Sharma, Ch. Satyanarayana, K. Sarjan Rao and Raghunandhan, T. 2020. Determinants of Diffusion of Animal Husbandry Innovations among Dairy Farmers of Andhra Pradesh. Int.J.Curr.Microbiol.App.Sci. 9(04): 2045-2051. doi: https://doi.org/10.20546/ijcmas.2020.904.244 